\title{
Arrhythmias in Complex Congenital Heart Disease
}

\author{
Robert M. Hayward, MD ${ }^{\star}$ and Zian H. Tseng, MD, MAS ${ }^{\dagger}$ \\ 'Division of Cardiology, Department of Medicine, University of California, San Francisco \\ tSection of Cardiac Electrophysiology, Division of Cardiology, Department of Medicine, University \\ of California, San Francisco
}

\begin{abstract}
Late after surgical repair of complex congenital heart disease, atrial arrhythmias are a major cause of morbidity, and ventricular arrhythmias and sudden cardiac death are a major cause of mortality. The six cases in this article highlight common challenges in the management of arrhythmias in the adult congenital heart disease population.
\end{abstract}

\section{Keywords}

atrial fibrillation; atrial flutter; catheter ablation; congenital heart disease; ventricular tachycardia

\section{Introduction}

Over one million adults are living with congenital heart disease (CHD) in the United States and this group now outnumbers children with CHD. ${ }^{1,2}$ Late after surgical repair of complex congenital lesions, atrial arrhythmias are a major cause of morbidity, and ventricular arrhythmias and sudden cardiac death (SCD) are a major cause of mortality. ${ }^{3-7}$ Arrhythmia mechanisms include reentry due substrate from previous surgeries, the long-term consequences of hemodynamic abnormalities such as chamber enlargement and hypertrophy, and direct results of congenital abnormalities, such as the presence of accessory pathways. It has been reported that the prevalence of atrial arrhythmias is $15 \%$ in adults with CHD; for patients with complex CHD, the lifetime risk of atrial arrhythmias is over $50 \% .^{8}$ Atrial arrhythmias in these patients are associated with increased risk of stroke, heart failure, and mortality. ${ }^{8}$ Ventricular arrhythmias are also common in CHD, especially in patients with tetralogy of Fallot (TOF), ventricular septal defect, Ebstein's anomaly and systemic right ventricles. Drug therapy is often inadequate for these patients. Amiodarone is often avoided in younger patients due to concerns over long-term toxicity; class IC agents may have lower efficacy than in other patient groups ${ }^{9}$ and may be contraindicated due to

(C) 2014 Elsevier Inc. All rights reserved.

Address for Correspondence: Zian H. Tseng, MD, MAS, Associate Professor of Medicine in Residence, Cardiac Electrophysiology Section, University of California-San Francisco 500 Parnassus Avenue, Box 1354, San Francisco, California 94143-1354, Phone: 415-476-5706, Fax: 415-476-6260, zhtseng@ medicine.ucsf.edu.

Publisher's Disclaimer: This is a PDF file of an unedited manuscript that has been accepted for publication. As a service to our customers we are providing this early version of the manuscript. The manuscript will undergo copyediting, typesetting, and review of the resulting proof before it is published in its final citable form. Please note that during the production process errors may be discovered which could affect the content, and all legal disclaimers that apply to the journal pertain. 
underlying structural heart disease. In experienced centers, catheter ablation has emerged as the preferred therapeutic option for atrial and ventricular arrhythmias in the CHD population. As increasing numbers of patients reach adulthood, the burden of arrhythmias and SCD are expected to increase even further and the need for device implantations ${ }^{10}$ and catheter ablation procedures will continue to grow. This review will focus on six cases that highlight common and important electrophysiology problems in the adult CHD population.

\section{Case I}

A 45-year-old woman with history of perimembranous VSD status-post patch repair, moderate residual RV enlargement, and supraventricular tachycardia (SVT) status-post ablation at another hospital 8 years prior was admitted with palpitations and SVT (Figure 1). Electrophysiology (EP) study revealed two intraatrial reentrant tachycardias (IARTs) involving a posterolateral right atrial scar (Figure 2). Radiofrequency catheter ablation of the isthmus within the scar terminated the arrhythmias (Figure 3).

The most common arrhythmia in older adults with CHD is IART. This is a macroreentrant circuit involving abnormal atrial tissue resulting from atriotomy incisions, fibrosis, or patches ${ }^{11-13}$ and characterized by large areas of low voltage with multiple heterogeneous channels. ${ }^{14}$ IART can be seen in any patient who has undergone atriotomy, such as this patient, but the incidence is particularly high for patients with dextro-transposition of the great arteries (D-TGA) status post Mustard ${ }^{15}$ or Senning repair and patients with a single ventricle status post Fontan. Fontan patients treated with older intraatrial lateral tunnel operations are at higher risk than those treated with extracardiac Fontan operations. ${ }^{16-20}$ Atrial rates in IART are typically $150-250 \mathrm{bpm}$ and 1:1 AV conduction can result in presyncope, syncope, or SCD. ${ }^{21}$ As in this patient, multiple circuits are common.

Catheter ablation has been used with success in experienced centers. Complete procedural success has been reported to be as high as $80 \%$ with the use of irrigated ablation catheters and electroanatomic mapping, but recurrence has been reported in about $40 \%$ of patients. Arrhythmia recurrence is more common for those with multiple circuits, atrial fibrillation, and Fontan physiology. ${ }^{22}$ Because IART has been associated with thromboembolism, ${ }^{23}$ adequate anticoagulation with periprocedural TEE guidance according to standard guidelines is recommended.

\section{Case II}

A 50-year-old man with D-TGA status post Mustard procedure presented with dyspnea on exertion and was found to have pulmonary venous baffle stenosis and right-to-left shunting suggesting a systemic venous baffle leak. At the time of stenting for the pulmonary venous baffle stenosis, he was found to be in atrial flutter at cycle-length $280 \mathrm{msec}$. Flutter waves were negative in the inferior leads and positive in V1 suggesting typical counterclockwise flutter. During the procedure the patient developed 1:1 AV conduction in atrial flutter and became hypotensive, requiring external cardioversion. After several weeks of anticoagulation with warfarin, he underwent EP study. Typical atrial flutter was induced and dependence on the cavotricuspid isthmus was proven with entrainment (Figure 4). Multiple radiofrequency lesions were placed in systemic venous atrium proximal to the baffle at 4 
o'clock on tricuspid annulus. Because the baffle prevented access to the anterior part of the cavo-tricuspid isthmus, the ablation catheter was then advanced via the baffle leak to the pulmonary venous (morphologic right) atrium and positioned along the cavo-tricuspid isthmus anterior and adjacent to the initial lesion set (Figure 5). The ablation line was then continued anteriorly towards the tricuspid (systemic AV) valve. After ablation, atrial flutter was not inducible. Three weeks later, the patient's baffle leak was closed percutaneously using two vascular plugs. The patient has been free from arrhythmia symptoms and atrial flutter at follow-up.

The patient underwent a follow-up event monitor for atrial arrhythmias prior to stopping anticoagulation. He did not have any atrial flutter but was found to have nonsustained ventricular tachycardia (NSVT), up to 6 beats in duration. Given moderate-to-severe systemic (RV) dysfunction, NSVT, prolonged QRS duration, and resting bradycardia, he underwent dual chamber ICD implantation.

D-TGA accounts for 3-7\% of congenital heart defects. ${ }^{24}$ Historically, most patients with DTGA were treated with atrial switch operations (Mustard or Senning baffles), but since the 1980s most patients have been treated with the arterial switch operation. However, most adults followed in CHD clinics underwent atrial switch repairs. These subjects are at high risk for congestive heart failure; ventricular arrhythmias and SCD are the leading cause of late mortality. ${ }^{25-28}$ In the largest retrospective study of these patients, ventricular tachycardia and SCD were correlated with NYHA class, systolic dysfunction of the systemic ventricle, and QRS duration (hazard ratio 13.6 for QRS duration $\geq 140 \mathrm{msec}$ ) but not with supraventricular arrhythmias. ${ }^{29}$ Another study reached different conclusions: that supraventricular arrhythmias, not QRS duration, were predictive of ventricular arrhythmias. ${ }^{30}$ However, the decision to place an ICD in this patient is largely extrapolated from primary prevention data in patients with nonischemic cardiomypathy (reduced function of the systemic ventricle and NSVT). ${ }^{31-34}$

Full access to the cavo-tricuspid isthmus via the systemic venous atrium in patients treated with older Mustard or Senning repairs is often limited by baffles. In these cases, completion of a cavo-tricuspid isthmus line often requires ablation in the systemic venous atrium followed by accessing the pulmonary venous atrium via either a retrograde approach or traversing the baffle. If there is no baffle leak present, access to the pulmonary venous atrium can be obtained through a trans-baffle puncture or retrograde aortic approach.

\section{Case III}

A 76-year-old woman with levo-transposition of the great arteries (L-TGA) presented with fatigue and dyspnea on exertion. She was found to have both atrial fibrillation and atrial flutter (Figure 6) and both of these arrhythmias recurred despite amiodarone and cardioversion. Because of the severe symptoms, she underwent EP study, which induced cavo-tricupid isthmus dependent atrial flutter and a roof-dependent IART. She underwent ablation of both tachycardias and pulmonary vein isolation (Figures 7 and 8).

As patients with CHD live longer, atrial fibrillation is an increasing problem. ${ }^{35}$ In one study of pulmonary vein antrum isolation in patients with CHD, similar success rates were 
reported to patients without CHD, although in $60 \%$ of CHD patients the only congenital abnormality was an atrial septal defect. ${ }^{36}$ Accessing the pulmonary venous atrium in patients with CHD can be technically more difficult with abnormal anatomy and baffles, but can be accomplished safely in most cases. Intracardiac echocardiography can be useful for trans-baffle puncture and identifying important anatomical structures in CHD patients. ${ }^{37,}, 38$ In patients with L-TGA, the electrophysiologist should be aware of the possibility of other abnormalities, such as ventricular septal defect and tricuspid (systemic AV valve) regurgitation. In addition, dual AV nodes have been reported and conduction usually occurs via the anteriorly situated AV node. ${ }^{39}$ The position of this node at the mitral-pulmonary continuity and the extended length of the His-Purkinje system are thought to render these structures susceptible to fibrosis; complete heart block is reported to occur at a rate of $\sim 2 \%$ / year in patients with L-TGA. ${ }^{40}$

\section{Case IV}

A 7-year-old girl with Ebstein's anomaly of the tricuspid valve presented with palpitations. She developed supraventricular tachycardia at 2 days of age, but this was controlled with propranolol and later with propafenone. At the age of 7 , she began experiencing palpitations 3-4 times per month and had two episodes of syncope while dancing. Electrocardiogram showed pre-excitation (Figure 9) and event monitoring demonstrated a regular, narrowcomplex tachycardia at a rate of $224 \mathrm{bpm}$. Due to symptoms and syncope, she underwent EP study. During atrial overdrive pacing, there was non-decremental, eccentric AV conduction with the earliest ventricular activation on the proximal coronary sinus catheter electrode pair. Orthodromic reciprocating tachycardia was induced with atrial extrastimulus pacing. During SVT, premature ventricular complexes introduced during His refractoriness advanced the subsequent atrial electrogram and reset the tachycardia. Based on these findings, a single manifest right posteroseptal accessory pathway was diagnosed and radiofrequency energy application just anterior to the coronary sinus os resulted in loss of preexcitation (Figures 10 and 11). Following this lesion, there was no antegrade or retrograde accessory pathway conduction observed. The patient has been free of arrhythmias at several years of follow-up.

Wolff-Parkinson-White syndrome (WPW) is the most common arrhythmia in Ebstein's anomaly but other arrhythmias, including atrial fibrillation, atrial flutter, AV nodal reentrant tachycardia, and ventricular tachycardia are seen in this patient population as well. ${ }^{41,42}$ Radiofrequency catheter ablation is the therapy of choice for WPW in suitable patients with Ebstein's anomaly. However, compared to catheter ablation of accessory pathways in patients without CHD, procedural success rates are lower and recurrence rates are higher ${ }^{43}$ due to the presence of multiple pathways, right-sided pathway predominance, ${ }^{44}$ and abnormal AV node location. Because atrial septal defect and patent foramen ovale are also common, these patients may be at increased risk for paradoxical embolism during catheter ablation. Intra-operative ablation of accessory pathways can also be considered for patients undergoing tricuspid valve surgery. ${ }^{42}$ 


\section{Case V}

A 46-year-old man with TOF status-post repair in childhood, severe tricuspid regurgitation (due to flail leaflet) and severe pulmonary regurgitation underwent EP study and ablation for typical atrial flutter and IART. EP study demonstrated inducible, unstable polymorphic ventricular tachycardia (PMVT) with triple extrastimuli. After tricuspid valve repair and pulmonary valve replacement, he underwent a follow-up EP study which induced unstable monomorphic ventricular tachycardia (MMVT) at a cycle-length of $260 \mathrm{msec}$ with a left bundle branch block superior axis morphology. For this reason, he underwent ICD implantation. Two years later, he had an appropriate ICD discharge for MMVT.

TOF accounts for about $10 \%$ of congenital heart defects. Surgical repair has good intermediate and long-term results ${ }^{45-49}$ and survival has improved dramatically over the last 25 years. ${ }^{50}$ However, ventricular arrhythmias are common and SCD is the leading cause of late mortality. ${ }^{4,51,52}$ Clinical sustained ventricular arrhythmias are reported to have a prevalence of $\sim 15 \%$ by 35 years of age, with increased incidence in even older patients. ${ }^{5,52}$ It has been reported that arrhythmias in these patients are correlated with QRS duration (especially over $180 \mathrm{msec}$ ), increase in QRS duration over time, number of prior surgeries, right ventricular dilation, the presence of an RVOT patch, pulmonary regurgitation, and LV diastolic dysfunction. ${ }^{52,53}$ Several studies have shown that inducibility of ventricular arrhythmias at EP study has good sensitivity and specificity for predicting subsequent ventricular arrhythmias or SCD. ${ }^{54-56}$ Importantly, MMVT and PMVT, both of which were induced in this patient, have been shown to be predictive of future events in the TOF population. ${ }^{55}$ Because EP testing is invasive and a positive study alone in low risk patients probably does not justify ICD placement, ${ }^{57,58} \mathrm{EP}$ study is reserved for patients with arrhythmia symptoms or abnormal results of other tests, such as rapid or frequent NSVT on Holter monitoring.

Due to areas of scar and slowed conduction in the right ventricle, TOF is the classic congenital heart defect resulting in MMVT. Because this is most commonly a macroreentrant circuit in scar of RV free wall or near the septal patch repair, the electrocardiogram in VT typically shows a left bundle branch block pattern with an inferior axis, but other morphologies can be seen as well. ${ }^{59}$ MMVT is also seen in CHD patients with ventriculotomy incisions, VSD patches, and Ebstein's anomaly.

ICDs, catheter ablation, and arrhythmia surgery are options for sustained VT or cardiac arrest in the CHD population. In TOF patients undergoing pulmonary valve replacement, intraoperative VT ablation has been used with success in experienced centers. ${ }^{60-64}$ Catheter ablation of MMVT has good success rates, ${ }^{65-68}$ but late ventricular arrhythmia recurrences are reported in the CHD population and as a result, ICDs are used as prophylaxis against sudden death. ${ }^{68,69}$

\section{Case VI}

A 29-year-old man with D-TGA status post Mustard procedure and history of sudden cardiac arrest due to ventricular fibrillation (VF) at 23 years of age was admitted with a transient ischemic attack (TIA) manifesting as 10 minutes of numbness in his right face, 
right arm, and right leg. After his cardiac arrest, he had undergone ICD placement. Due to lead fracture, he had undergone lead revision 4 years later and 6 months prior to his presentation for TIA, he had undergone lead revision at another hospital due to T-wave oversensing. Chest x-ray and transthoracic echocardiogram demonstrated that the ICD lead was incorrectly placed in the right (systemic) ventricle via a baffle leak (Figure 12). The device was extracted and a new lead was inserted into the left (subpulmonic) ventricle and the patient was placed on chronic anticoagulation with no further neurological symptoms.

The majority of adult CHD patients with an indication for ICD placement can undergo transvenous system implantation. Lead failure is not uncommon, especially in younger patients..$^{70}$ In addition, caution must be taken in lead placement with abnormal venous anatomy. If baffle leaks are present, this can impact decisions regarding anticoagulation and it is possible to inadvertently place leads in the systemic ventricle, as in this case. These should be closed prior to lead implantation to prevent systemic thromboemboli. Some patients have anatomy that precludes access to the subpulmonic ventricle (baffle obstruction or stenosis) and some patients with a single ventricle or right-to-left shunts are at risk for thromboembolism with transvenous ICD placement. In these patients, nontransvenous systems are preferred.

Additionally, patients with CHD are at risk for PMVT and ventricular fibrillation (VF) due to pressure and volume overload, chamber enlargement, and hypoxemia. PMVT and VF are most commonly seen in congenital aortic stenosis, systemic RVs, and Eisenmenger's syndrome. ${ }^{71}$ This patient initially underwent ICD placement due to VF in the setting of an abnormal systemic ventricle. It is important, however, to note that due to hemodynamic status and comorbidities, not all sudden deaths in high-risk patients with CHD are due to an arrhythmic cause. ${ }^{72}$

\section{Summary}

Atrial and ventricular arrhythmias are a common cause of morbidity and mortality in the growing population of adults with CHD. Patients with high-risk CHD lesions such as dTGA, 1-TGA, or Tetralogy of Fallot should be monitored routinely for arrhythmias and associated symptoms. Catheter ablation is an excellent therapeutic option for a variety of arrhythmias observed in these patients when performed in experienced centers by operators familiar with abnormal cardiac anatomy and associated abnormalities, such as residual shunts. ICD implantation is recommended for cardiac arrest survivors and CHD patients with sustained VTs discovered on electrophysiology study. In planning both catheter ablation and device implantation procedures, clinicians should review specific anatomy and all surgical records, and obtain detailed imaging to define possible obstructions or stenosis in vascular pathways.

\section{Acknowledgments}

The authors would like to thank Ronn Tanel, MD for contributing the case of WPW in Ebstein's anomaly and Edward Gerstenfeld, MD for contributing the case of pulmonary vein isolation in L-TGA.

Financial Support: This work was supported in part by NIH/NHLBI 5R01 HL102090 (Dr. Tseng). 
Disclosures: Dr. Tseng has received minor honoraria from Biotronik. Dr. Hayward has received an educational travel grant from Medtronic.

\section{References}

1. Hoffman JI, Kaplan S, Liberthson RR. Prevalence of congenital heart disease. Am Heart J. 2004; 147(3):425-439. [PubMed: 14999190]

2. Warnes CA, Liberthson R, Danielson GK, et al. Task force 1: the changing profile of congenital heart disease in adult life. J Am Coll Cardiol. 2001; 37(5):1170-1175. [PubMed: 11300418]

3. Oechslin EN, Harrison DA, Connelly MS, et al. Mode of death in adults with congenital heart disease. Am J Cardiol. 2000; 86(10):1111-1116. [PubMed: 11074209]

4. Nollert G, Fischlein T, Bouterwek S, et al. Long-term survival in patients with repair of tetralogy of Fallot: 36-year follow-up of 490 survivors of the first year after surgical repair. J Am Coll Cardiol. 1997; 30(5):1374-1383. [PubMed: 9350942]

5. Gatzoulis MA, Balaji S, Webber SA, et al. Risk factors for arrhythmia and sudden cardiac death late after repair of tetralogy of Fallot: a multicentre study. Lancet. 2000; 356(9234):975-981. [PubMed: 11041398]

6. Abadir S, Khairy P. Electrophysiology and adult congenital heart disease: advances and options. Prog Cardiovasc Dis. 2011; 53(4):281-292. [PubMed: 21295670]

7. Pillutla P, Shetty KD, Foster E. Mortality associated with adult congenital heart disease: Trends in the US population from 1979 to 2005. Am Heart J. 2009; 158(5):874-879. [PubMed: 19853711]

8. Bouchardy J, Therrien J, Pilote L, et al. Atrial arrhythmias in adults with congenital heart disease. Circulation. 2009; 120(17):1679-1686. [PubMed: 19822808]

9. Garson A Jr, Bink-Boelkens M, Hesslein PS, et al. Atrial flutter in the young: a collaborative study of 380 cases. J Am Coll Cardiol. 1985; 6(4):871-878. [PubMed: 4031302]

10. Opotowsky AR, Siddiqi OK, Webb GD. Trends in hospitalizations for adults with congenital heart disease in the U.S. J Am Coll Cardiol. 2009; 54(5):460-467. [PubMed: 19628123]

11. Triedman JK, Bergau DM, Saul JP, et al. Efficacy of radiofrequency ablation for control of intraatrial reentrant tachycardia in patients with congenital heart disease. J Am Coll Cardiol. 1997; 30(4):1032-1038. [PubMed: 9316535]

12. Kalman JM, VanHare GF, Olgin JE, et al. Ablation of 'incisional' reentrant atrial tachycardia complicating surgery for congenital heart disease. Use of entrainment to define a critical isthmus of conduction. Circulation. 1996; 93(3):502-512. [PubMed: 8565168]

13. Delacretaz E, Ganz LI, Soejima K, et al. Multi atrial maco-re-entry circuits in adults with repaired congenital heart disease: entrainment mapping combined with three-dimensional electroanatomic mapping. J Am Coll Cardiol. 2001; 37(6):1665-1676. [PubMed: 11345382]

14. Nakagawa H, Shah N, Matsudaira K, et al. Characterization of reentrant circuit in macroreentrant right atrial tachycardia after surgical repair of congenital heart disease: isolated channels between scars allow "focal" ablation. Circulation. 2001; 103(5):699-709. [PubMed: 11156882]

15. Flinn CJ, Wolff GS, Dick M 2nd, et al. Cardiac rhythm after the Mustard operation for complete transposition of the great arteries. The New England journal of medicine. 1984; 310(25):16351638. [PubMed: 6727935]

16. Ghai A, Harris L, Harrison DA, et al. Outcomes of late atrial tachyarrhythmias in adults after the Fontan operation. J Am Coll Cardiol. 2001; 37(2):585-592. [PubMed: 11216983]

17. Ovroutski S, Dahnert I, Alexi-Meskishvili V, et al. Preliminary analysis of arrhythmias after the Fontan operation with extracardiac conduit compared with intra-atrial lateral tunnel. The Thoracic and cardiovascular surgeon. 2001; 49(6):334-337. [PubMed: 11745055]

18. Nurnberg JH, Ovroutski S, Alexi-Meskishvili V, et al. New onset arrhythmias after the extracardiac conduit Fontan operation compared with the intraatrial lateral tunnel procedure: early and midterm results. The Annals of thoracic surgery. 2004; 78(6):1979-1988. discussion 1988. [PubMed: 15561013]

19. Stamm C, Friehs I, Mayer JE Jr, et al. Long-term results of the lateral tunnel Fontan operation. The Journal of thoracic and cardiovascular surgery. 2001; 121(1):28-41. [PubMed: 11135157] 
20. Fishberger SB, Wernovsky G, Gentles TL, et al. Factors that influence the development of atrial flutter after the Fontan operation. The Journal of thoracic and cardiovascular surgery. 1997; 113(1):80-86. [PubMed: 9011705]

21. Walsh EP. Interventional electrophysiology in patients with congenital heart disease. Circulation. 2007; 115(25):3224-3234. [PubMed: 17592091]

22. Triedman JK, Alexander ME, Love BA, et al. Influence of patient factors and ablative technologies on outcomes of radiofrequency ablation of intra-atrial re-entrant tachycardia in patients with congenital heart disease. J Am Coll Cardiol. 2002; 39(11):1827-1835. [PubMed: 12039499]

23. Feltes TF, Friedman RA. Transesophageal echocardiographic detection of atrial thrombi in patients with nonfibrillation atrial tachyarrhythmias and congenital heart disease. J Am Coll Cardiol. 1994; 24(5):1365-1370. [PubMed: 7930262]

24. Reller MD, Strickland MJ, Riehle-Colarusso T, et al. Prevalence of congenital heart defects in metropolitan Atlanta, 1998-2005. The Journal of pediatrics. 2008; 153(6):807-813. [PubMed: 18657826]

25. Puley G, Siu S, Connelly M, et al. Arrhythmia and survival in patients $>18$ years of age after the mustard procedure for complete transposition of the great arteries. The American journal of cardiology. 1999; 83(7):1080-1084. [PubMed: 10190524]

26. Silka MJ, Hardy BG, Menashe VD, et al. A population-based prospective evaluation of risk of sudden cardiac death after operation for common congenital heart defects. J Am Coll Cardiol. 1998; 32(1):245-251. [PubMed: 9669277]

27. Gelatt M, Hamilton RM, McCrindle BW, et al. Arrhythmia and mortality after the Mustard procedure: a 30-year single-center experience. J Am Coll Cardiol. 1997; 29(1):194-201. [PubMed: 8996314]

28. Sarkar D, Bull C, Yates R, et al. Comparison of long-term outcomes of atrial repair of simple transposition with implications for a late arterial switch strategy. Circulation. 1999; 100(19 Suppl):II176-181. [PubMed: 10567300]

29. Schwerzmann M, Salehian O, Harris L, et al. Ventricular arrhythmias and sudden death in adults after a Mustard operation for transposition of the great arteries. Eur Heart J. 2009; 30(15):18731879. [PubMed: 19465439]

30. Kammeraad JA, van Deurzen CH, Sreeram N, et al. Predictors of sudden cardiac death after Mustard or Senning repair for transposition of the great arteries. J Am Coll Cardiol. 2004; 44(5): 1095-1102. [PubMed: 15337224]

31. Bardy GH, Lee KL, Mark DB, et al. Amiodarone or an implantable cardioverterdefibrillator for congestive heart failure. The New England journal of medicine. 2005; 352(3):225-237. [PubMed: 15659722]

32. Kadish A, Dyer A, Daubert JP, et al. Prophylactic defibrillator implantation in patients with nonischemic dilated cardiomyopathy. The New England journal of medicine. 2004; 350(21):21512158. [PubMed: 15152060]

33. Epstein AE, DiMarco JP, Ellenbogen KA, et al. ACC/AHA/HRS 2008 Guidelines for DeviceBased Therapy of Cardiac Rhythm Abnormalities: a report of the American College of Cardiology/American Heart Association Task Force on Practice Guidelines (Writing Committee to Revise the ACC/AHA/NASPE 2002 Guideline Update for Implantation of Cardiac Pacemakers and Antiarrhythmia Devices): developed in collaboration with the American Association for Thoracic Surgery and Society of Thoracic Surgeons. Circulation. 2008; 117(21):e350-408. [PubMed: 18483207]

34. Zipes DP, Camm AJ, Borggrefe M, et al. ACC/AHA/ESC 2006 guidelines for management of patients with ventricular arrhythmias and the prevention of sudden cardiac death: a report of the American College of Cardiology/American Heart Association Task Force and the European Society of Cardiology Committee for Practice Guidelines (Writing Committee to Develop Guidelines for Management of Patients With Ventricular Arrhythmias and the Prevention of Sudden Cardiac Death). J Am Coll Cardiol. 2006; 48(5):e247-346. [PubMed: 16949478]

35. Kirsh JA, Walsh EP, Triedman JK. Prevalence of and risk factors for atrial fibrillation and intraatrial reentrant tachycardia among patients with congenital heart disease. The American journal of cardiology. 2002; 90(3):338-340. [PubMed: 12127629] 
36. Philip F, Muhammad KI, Agarwal S, et al. Pulmonary vein isolation for the treatment of drugrefractory atrial fibrillation in adults with congenital heart disease. Congenit Heart Dis. 2012; 7(4): 392-399. [PubMed: 22469422]

37. Peichl P, Kautzner J, Gebauer R. Ablation of atrial tachycardias after correction of complex congenital heart diseases: utility of intracardiac echocardiography. Europace : European pacing, arrhythmias, and cardiac electrophysiology : journal of the working groups on cardiac pacing, arrhythmias, and cardiac cellular electrophysiology of the European Society of Cardiology. 2009; 11(1):48-53.

38. Banchs JE, Patel P, Naccarelli GV, et al. Intracardiac echocardiography in complex cardiac catheter ablation procedures. Journal of interventional cardiac electrophysiology : an international journal of arrhythmias and pacing. 2010; 28(3):167-184. [PubMed: 20480388]

39. Anderson RH, Becker AE, Arnold R, et al. The conducting tissues in congenitally corrected transposition. Circulation. 1974; 50(5):911-923. [PubMed: 4430094]

40. Warnes CA. Transposition of the great arteries. Circulation. 2006; 114(24):2699-2709. [PubMed: 17159076]

41. Reich JD, Auld D, Hulse E, et al. The Pediatric Radiofrequency Ablation Registry's experience with Ebstein's anomaly. Pediatric Electrophysiology Society. J Cardiovasc Electrophysiol. 1998; 9(12):1370-1377. [PubMed: 9869537]

42. Khositseth A, Danielson GK, Dearani JA, et al. Supraventricular tachyarrhythmias in Ebstein anomaly: management and outcome. The Journal of thoracic and cardiovascular surgery. 2004; 128(6):826-833. [PubMed: 15573066]

43. Chetaille P, Walsh EP, Triedman JK. Outcomes of radiofrequency catheter ablation of atrioventricular reciprocating tachycardia in patients with congenital heart disease. Heart rhythm : the official journal of the Heart Rhythm Society. 2004; 1(2):168-173. [PubMed: 15851148]

44. Etheridge SP. Radiofrequency catheter ablation of left-sided accessory pathways in pediatric patients. Progress in pediatric cardiology. 2001; 13(1):11-24. [PubMed: 11413055]

45. Hennein HA, Mosca RS, Urcelay G, et al. Intermediate results after complete repair of tetralogy of Fallot in neonates. The Journal of thoracic and cardiovascular surgery. 1995; 109(2):332-342. 344. discussion 342-333. [PubMed: 7531798]

46. Norgaard MA, Lauridsen P, Helvind M, et al. Twenty-to-thirty-seven-year follow-up after repair for Tetralogy of Fallot. European journal of cardio-thoracic surgery : official journal of the European Association for Cardio-thoracic Surgery. 1999; 16(2):125-130. [PubMed: 10485408]

47. Nakazawa M, Shinohara T, Sasaki A, et al. Arrhythmias late after repair of tetralogy of fallot: a Japanese Multicenter Study. Circulation journal : official journal of the Japanese Circulation Society. 2004; 68(2):126-130. [PubMed: 14745146]

48. Murphy JG, Gersh BJ, Mair DD, et al. Long-term outcome in patients undergoing surgical repair of tetralogy of Fallot. The New England journal of medicine. 1993; 329(9):593-599. [PubMed: 7688102]

49. Walsh EP, Rockenmacher S, Keane JF, et al. Late results in patients with tetralogy of Fallot repaired during infancy. Circulation. 1988; 77(5):1062-1067. [PubMed: 3359587]

50. Khairy P, Ionescu-Ittu R, Mackie AS, et al. Changing mortality in congenital heart disease. J Am Coll Cardiol. 2010; 56(14):1149-1157. [PubMed: 20863956]

51. Le Gloan L, Khairy P. Management of arrhythmias in patients with tetralogy of Fallot. Curr Opin Cardiol. 2011; 26(1):60-65. [PubMed: 21076290]

52. Khairy P, Aboulhosn J, Gurvitz MZ, et al. Arrhythmia burden in adults with surgically repaired tetralogy of Fallot: a multi-institutional study. Circulation. 2010; 122(9):868-875. [PubMed: 20713900]

53. Gatzoulis MA, Till JA, Somerville J, et al. Mechanoelectrical interaction in tetralogy of Fallot. QRS prolongation relates to right ventricular size and predicts malignant ventricular arrhythmias and sudden death. Circulation. 1995; 92(2):231-237. [PubMed: 7600655]

54. Dietl CA, Cazzaniga ME, Dubner SJ, et al. Life-threatening arrhythmias and RV dysfunction after surgical repair of tetralogy of Fallot. Comparison between transventricular and transatrial approaches. Circulation. 1994; 90(5 Pt 2):II7-12. [PubMed: 7955286] 
55. Khairy P, Landzberg MJ, Gatzoulis MA, et al. Value of programmed ventricular stimulation after tetralogy of fallot repair: a multicenter study. Circulation. 2004; 109(16):1994-2000. [PubMed: 15051640]

56. Alexander ME, Walsh EP, Saul JP, et al. Value of programmed ventricular stimulation in patients with congenital heart disease. J Cardiovasc Electrophysiol. 1999; 10(8):1033-1044. [PubMed: 10466482]

57. Khairy P. Programmed ventricular stimulation for risk stratification in patients with tetralogy of Fallot: a Bayesian perspective. Nat Clin Pract Cardiovasc Med. 2007; 4(6):292-293. [PubMed: 17522719]

58. Khairy P, Dore A, Poirier N, et al. Risk stratification in surgically repaired tetralogy of Fallot. Expert Rev Cardiovasc Ther. 2009; 7(7):755-762. [PubMed: 19589112]

59. Zeppenfeld K, Schalij MJ, Bartelings MM, et al. Catheter ablation of ventricular tachycardia after repair of congenital heart disease: electroanatomic identification of the critical right ventricular isthmus. Circulation. 2007; 116(20):2241-2252. [PubMed: 17967973]

60. Harrison DA, Harris L, Siu SC, et al. Sustained ventricular tachycardia in adult patients late after repair of tetralogy of Fallot. J Am Coll Cardiol. 1997; 30(5):1368-1373. [PubMed: 9350941]

61. Karamlou T, Silber I, Lao R, et al. Outcomes after late reoperation in patients with repaired tetralogy of Fallot: the impact of arrhythmia and arrhythmia surgery. Ann Thorac Surg. 2006; 81(5):1786-1793. discussion 1793. [PubMed: 16631673]

62. Oechslin EN, Harrison DA, Harris L, et al. Reoperation in adults with repair of tetralogy of fallot: indications and outcomes. J Thorac Cardiovasc Surg. 1999; 118(2):245-251. [PubMed: 10424997]

63. Therrien J, Siu SC, Harris L, et al. Impact of pulmonary valve replacement on arrhythmia propensity late after repair of tetralogy of Fallot. Circulation. 2001; 103(20):2489-2494. [PubMed: 11369690]

64. Misaki T, Tsubota M, Watanabe G, et al. Surgical treatment of ventricular tachycardia after surgical repair of tetralogy of Fallot. Relation between intraoperative mapping and histological findings. Circulation. 1994; 90(1):264-271. [PubMed: 8026007]

65. Burton ME, Leon AR. Radiofrequency catheter ablation of right ventricular outflow tract tachycardia late after complete repair of tetralogy of Fallot using the pace mapping technique. Pacing Clin Electrophysiol. 1993; 16(12):2319-2325. [PubMed: 7508611]

66. Goldner BG, Cooper R, Blau W, et al. Radiofrequency catheter ablation as a primary therapy for treatment of ventricular tachycardia in a patient after repair of tetralogy of Fallot. Pacing Clin Electrophysiol. 1994; 17(8):1441-1446. [PubMed: 7971406]

67. Gonska BD, Cao K, Raab J, et al. Radiofrequency catheter ablation of right ventricular tachycardia late after repair of congenital heart defects. Circulation. 1996; 94(8):1902-1908. [PubMed: 8873666]

68. Morwood JG, Triedman JK, Berul CI, et al. Radiofrequency catheter ablation of ventricular tachycardia in children and young adults with congenital heart disease. Heart rhythm : the official journal of the Heart Rhythm Society. 2004; 1(3):301-308. [PubMed: 15851174]

69. Khairy P, Stevenson WG. Catheter ablation in tetralogy of Fallot. Heart Rhythm. 2009; 6(7):10691074. [PubMed: 19560094]

70. Alexander ME, Cecchin F, Walsh EP, et al. Implications of implantable cardioverter defibrillator therapy in congenital heart disease and pediatrics. J Cardiovasc Electrophysiol. 2004; 15(1):72-76. [PubMed: 15028076]

71. Sherwin ED, Triedman JK, Walsh EP. Update on interventional electrophysiology in congenital heart disease: evolving solutions for complex hearts. Circ Arrhythm Electrophysiol. 2013; 6(5): 1032-1040. [PubMed: 24129205]

72. Hayward RM, Ursell PC, Foster E, et al. Sudden Death Due to Nonarrhythmic Cause in a Patient with L-TGA. Annals of noninvasive electrocardiology : the official journal of the International Society for Holter and Noninvasive Electrocardiology, Inc. 2013 


\section{Abbreviations}

$\begin{array}{ll}\text { CHD } & \text { congenital heart disease } \\ \text { D-TGA } & \text { dextro-transposition of the great arteries } \\ \text { EP } & \text { electrophysiology } \\ \text { L-TGA } & \text { levo-transposition of the great arteries } \\ \text { MMVT } & \text { monomorphic ventricular tachycardia } \\ \text { NSVT } & \text { nonsustained ventricular tachycardia } \\ \text { PMVT } & \text { polymorphic ventricular tachycardia } \\ \text { SCD } & \text { sudden cardiac death } \\ \text { SVT } & \text { supraventricular tachycardia } \\ \text { TOF } & \text { tetralogy of Fallot } \\ \text { TIA } & \text { transient ischemic attack } \\ \text { VF } & \text { ventricular fibrillation } \\ \text { WPW } & \text { Wolff-Parkinson-White syndrome }\end{array}$




\section{Key Points}

- Atrial and ventricular arrhythmias are a common cause of morbidity and mortality in the growing population of adults with congenital heart disease.

- Patients with high-risk CHD lesions such as d-TGA, 1-TGA, or tetralogy of Fallot should be monitored routinely for arrhythmias and associated symptoms.

- With the aid of electroanatomic mapping and newer irrigated radiofrequency energy delivery, catheter ablation is an excellent therapeutic option for a variety of arrhythmias observed in these patients when performed in experienced centers.

- ICD implantation is recommended for cardiac arrest survivors and CHD patients with sustained VT discovered on electrophysiology study.

- In planning both catheter ablation and device implantation procedures, clinicians should review specific anatomy and surgical records, obtain imaging to define possible obstructions or stenosis in vascular pathways, and be aware of associated congenital abnormalities. 


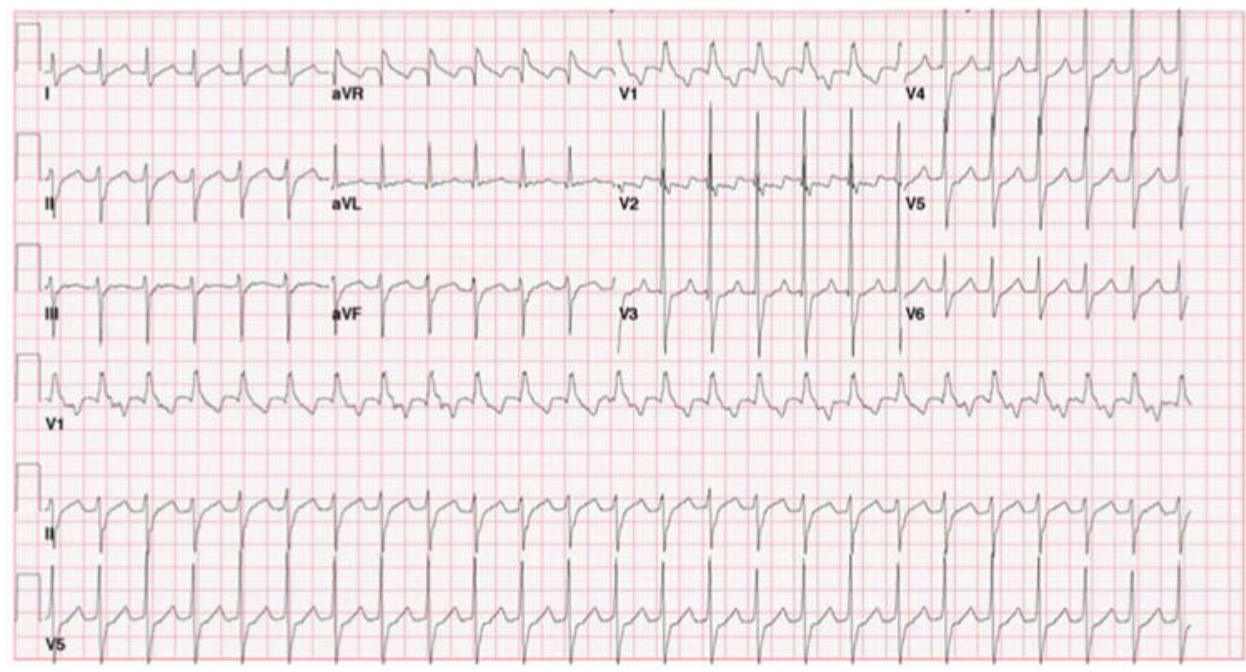

Figure 1.

Surface electrocardiogram of intraatrial reentrant tachycardia with 1:1 AV conduction. 


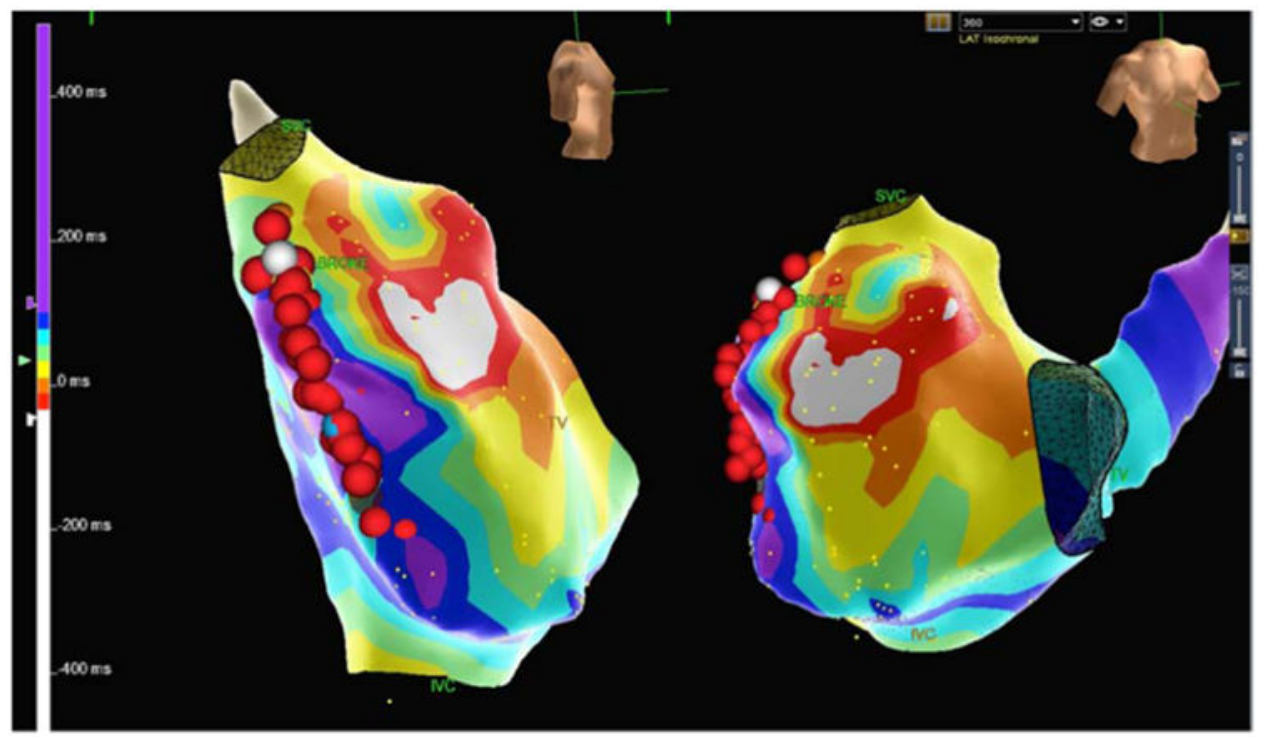

Figure 2.

Electroanatomic activation map demonstrating slow conduction in the isthmus of the intraatrial reentrant tachycardia circuit (purple areas) in the posterolateral right atrium at the site of a previous atriotomy incision. Ablation through this isthmus resulted in termination of tachycardia (white sphere); the RF lesion set was completed by connecting the areas of low voltage in the atriotomy incision to areas of normal voltage. 

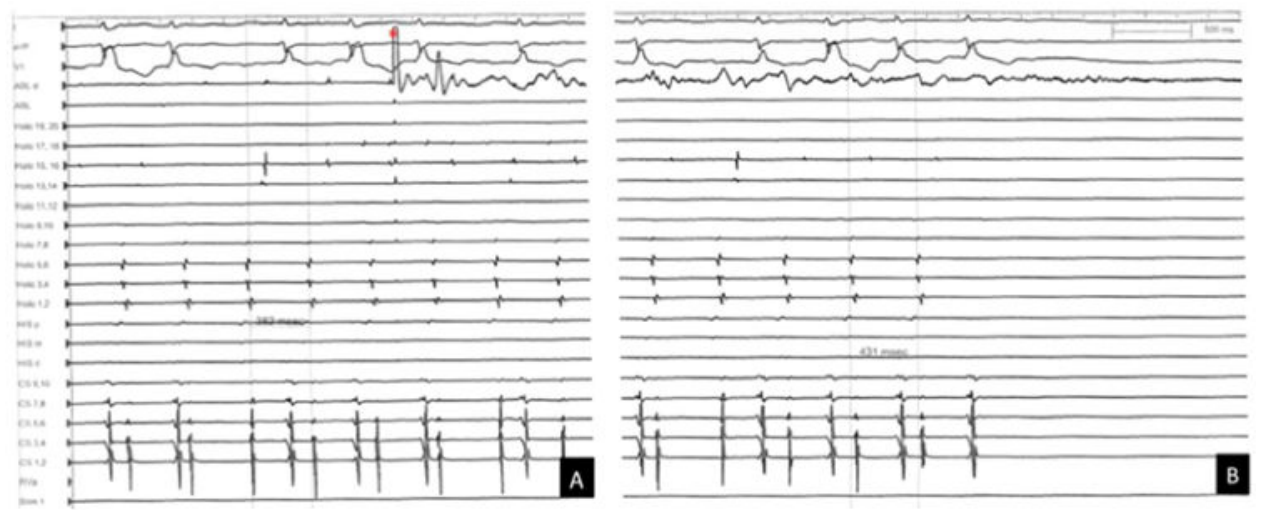

Figure 3.

A: Prior to the onset of radiofrequency energy application (*), intracardiac electrograms in intraatrial reentrant tachycardia demonstrate a diastolic signal on the ablation catheter representing conduction within the isthmus of the scar. B: During radiofrequency ablation, the tachycardia cycle length increases by $50 \mathrm{msec}$ prior to termination. 

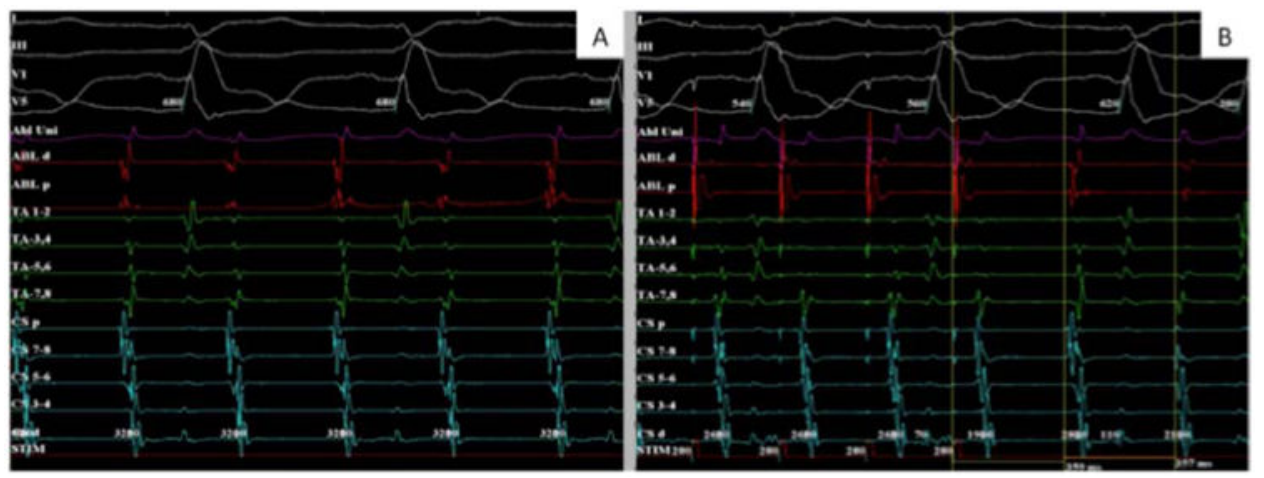

Figure 4.

A: Atrial flutter. B: The post-pacing interval after overdrive pacing from the cavotricuspid isthmus (Abl d) was equal to the tachycardia cycle length. 

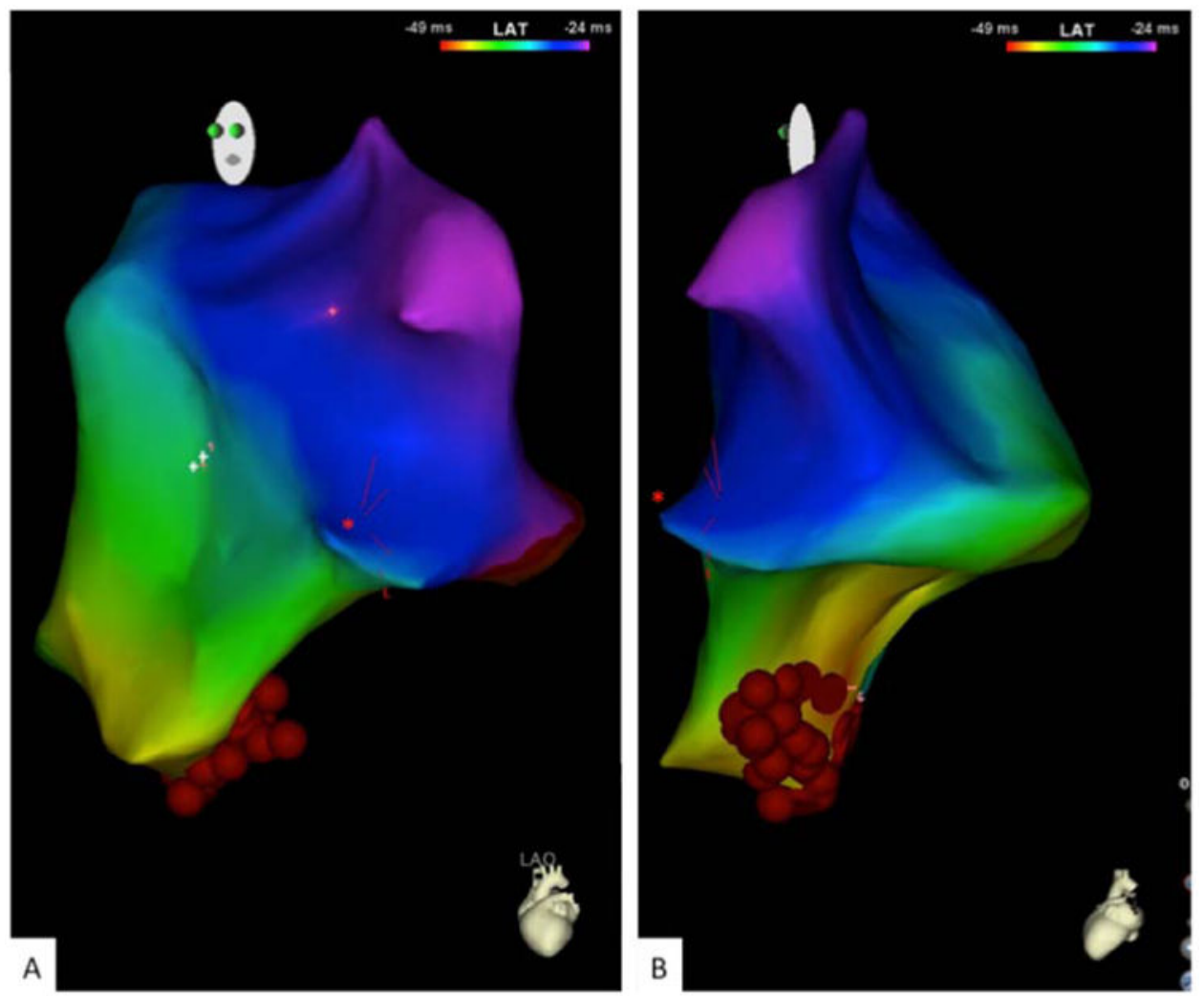

Figure 5.

LAO (A) and left lateral (B) electroanatomic activation map systemic venous atrium. Completion of the line across the cavo-tricuspid isthmus required accessing the pulmonary venous atrium via a baffle leak $(*)$. 


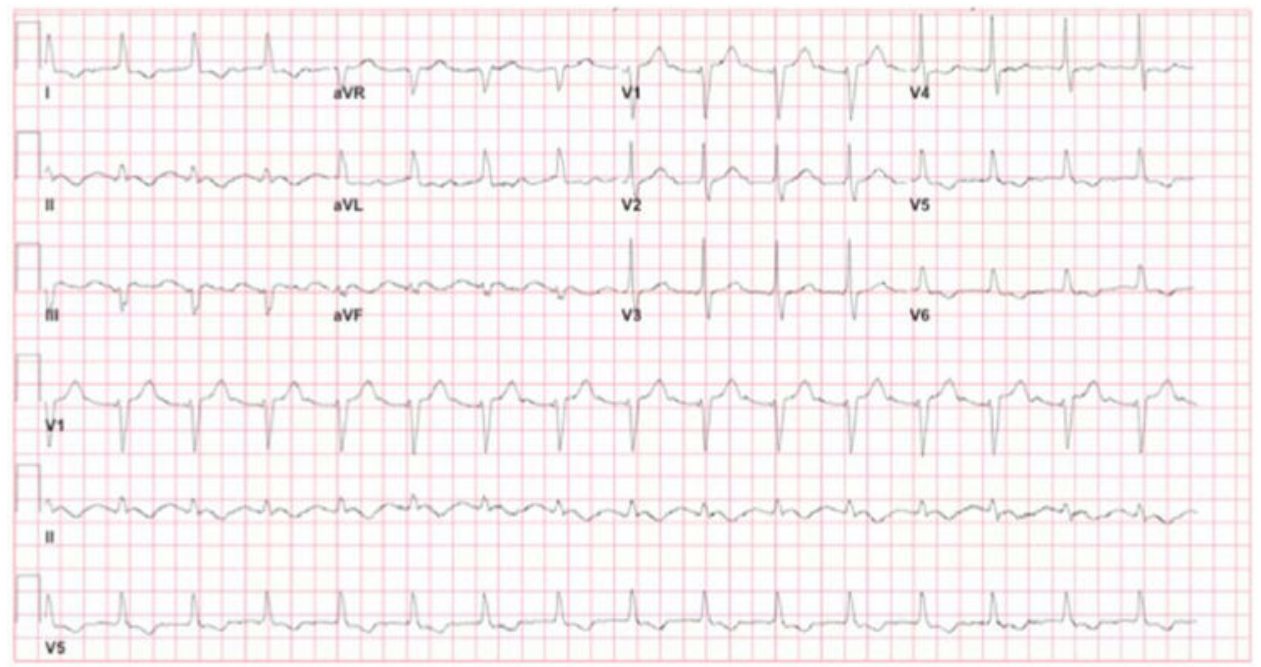

Figure 6.

Atrial flutter with 2:1 AV conduction. Note the absence of septal q-waves in the lateral precordial leads due to right-to-left depolarization of the interventricular septum in levotransposition of the great arteries. 


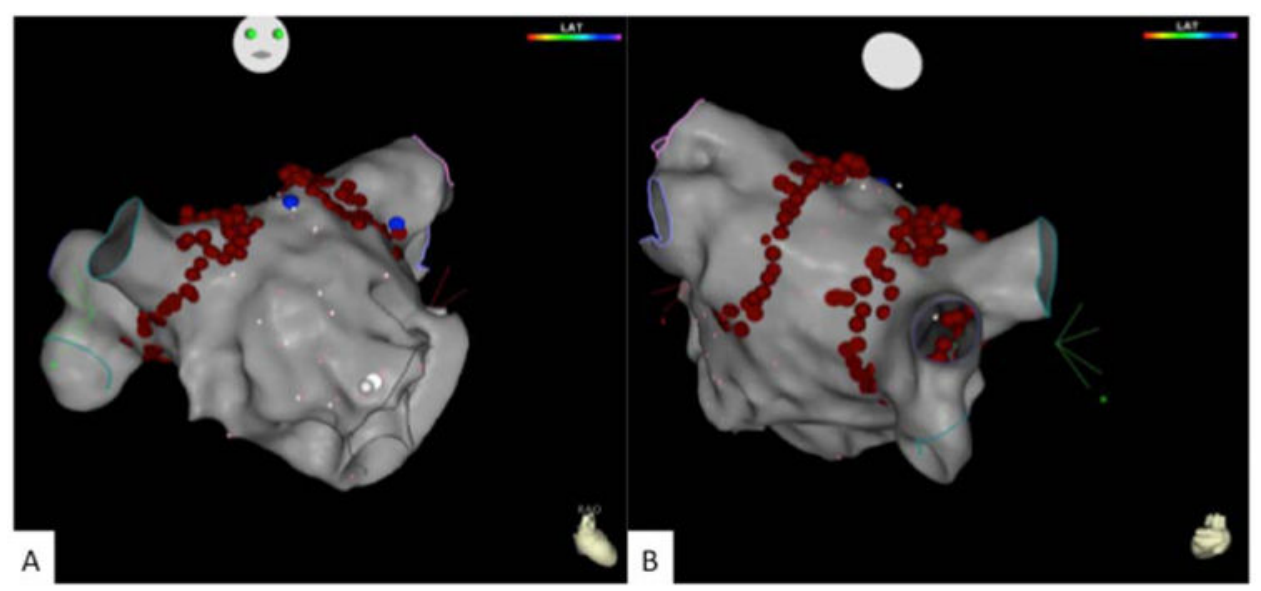

Figure 7.

A: RAO view of the normally-positioned left atrium after isolation of the pulmonary veins. B: Posteroanterior view of the left atrium after pulmonary vein isolation. In levotransposition of the great arteries, the left atrium connects to the right (systemic) ventricle via the tricuspid valve. 


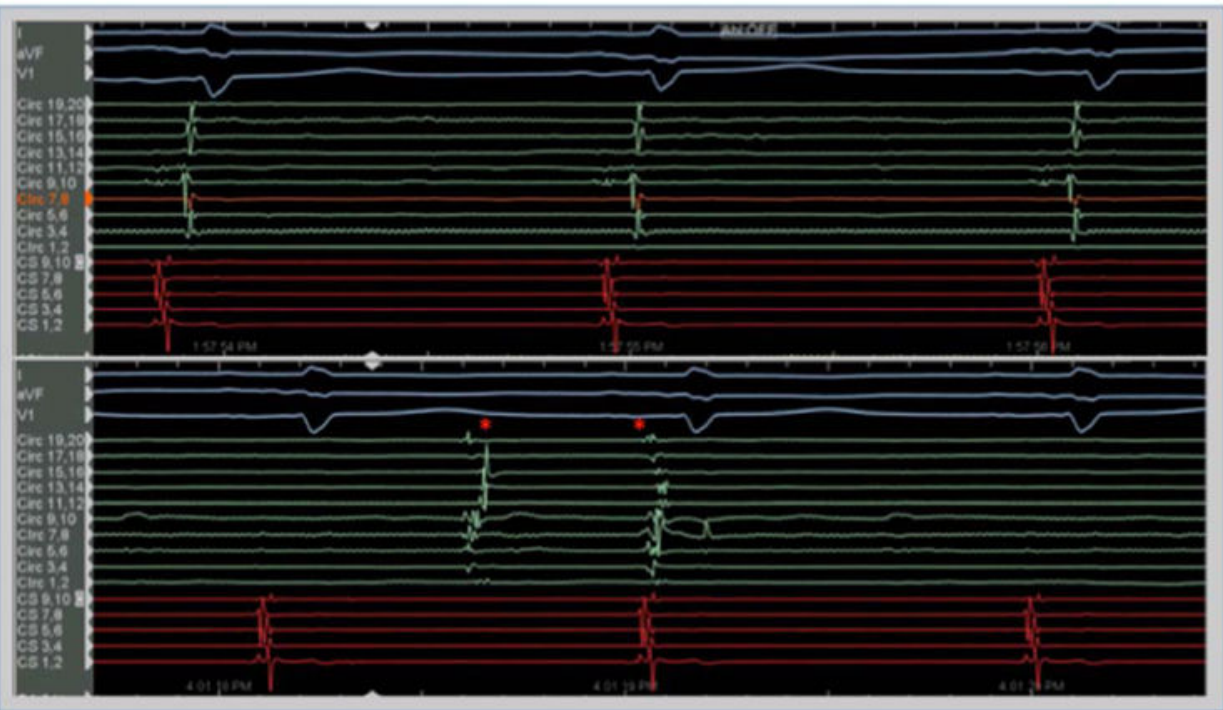

Figure 8.

Top: Sinus rhythm with conduction into left upper pulmonary vein (LUPV) prior to ablation. Bottom: Dissociation of LUPV potentials $\left(^{*}\right)$ after pulmonary vein isolation. 


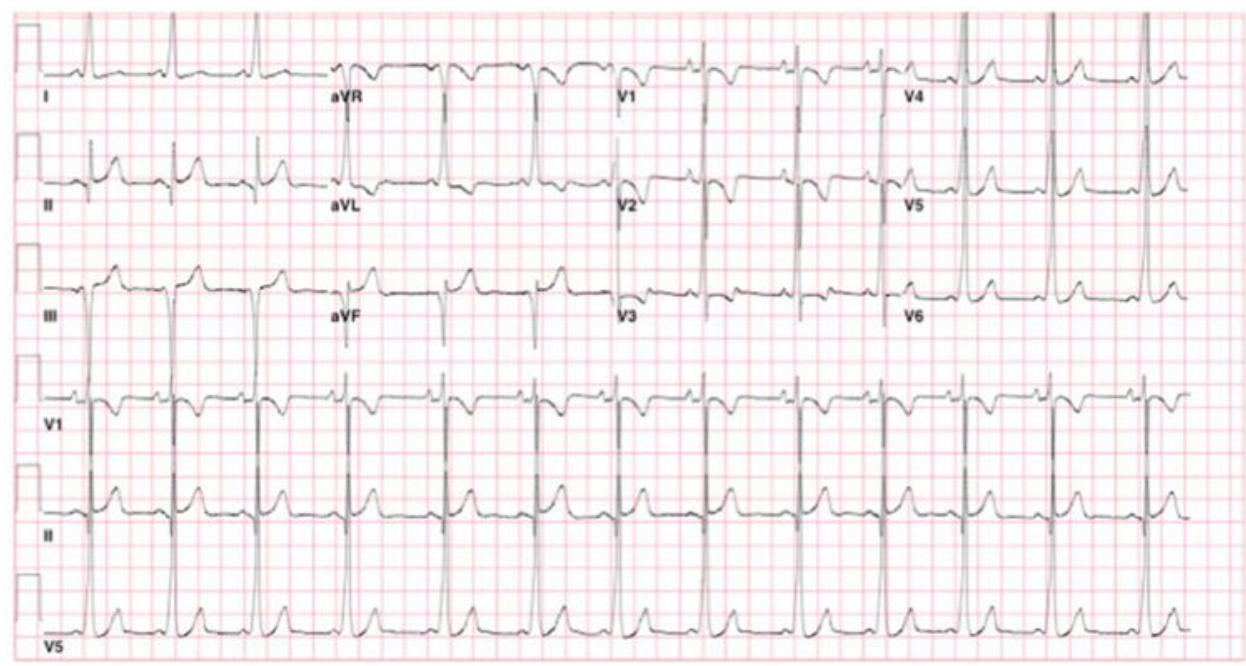

Figure 9.

Baseline ECG showing pre-excitation. The V2 precordial transition with a dominant R-wave in lead I suggests a right-sided accessory pathway. As is common with posteroseptal accessory pathways, there is a pseudo inferior myocardial infarction pattern in the inferior leads. 


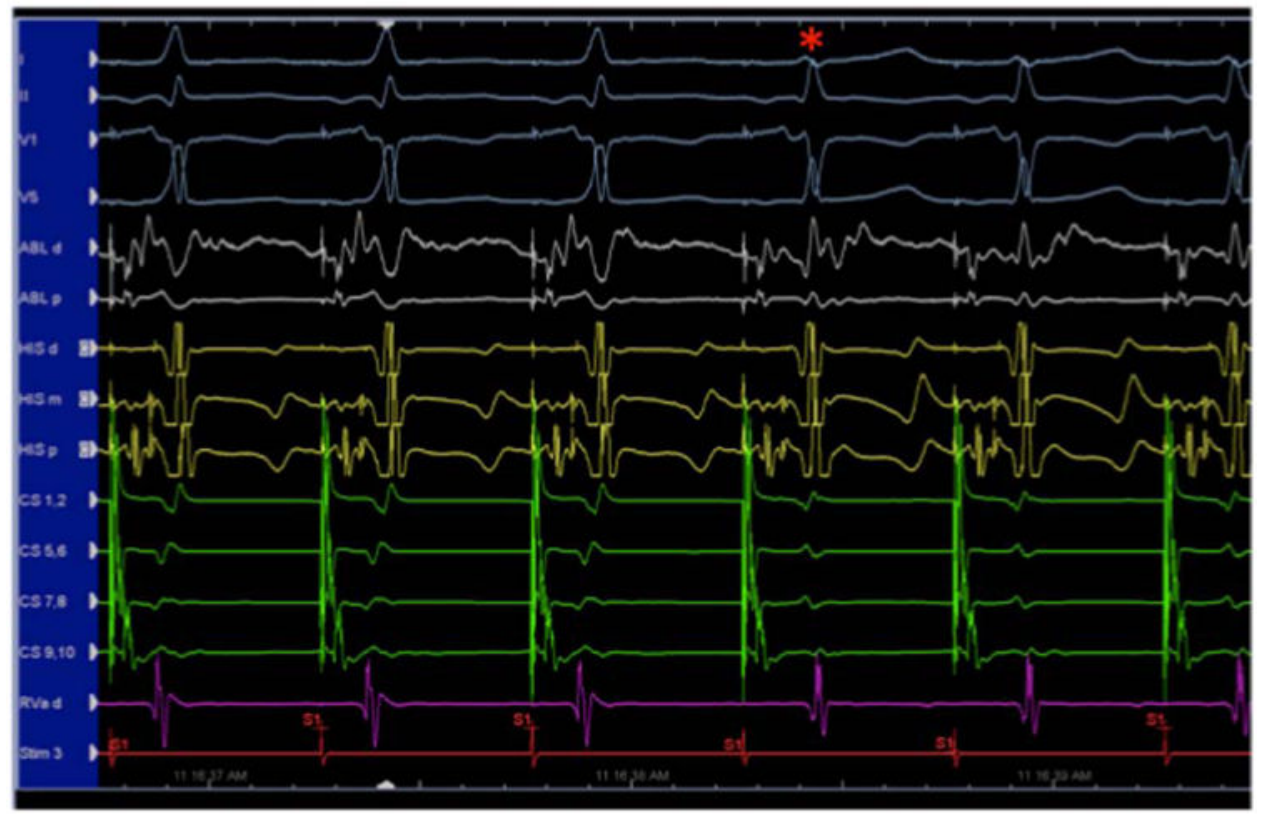

Figure 10.

During RF ablation while pacing the atrium, loss of pre-excitation $(*)$ and delay of the earliest ventricular electrogram on the proximal coronary sinus catheter electrode (CS 9,10) were noted. 


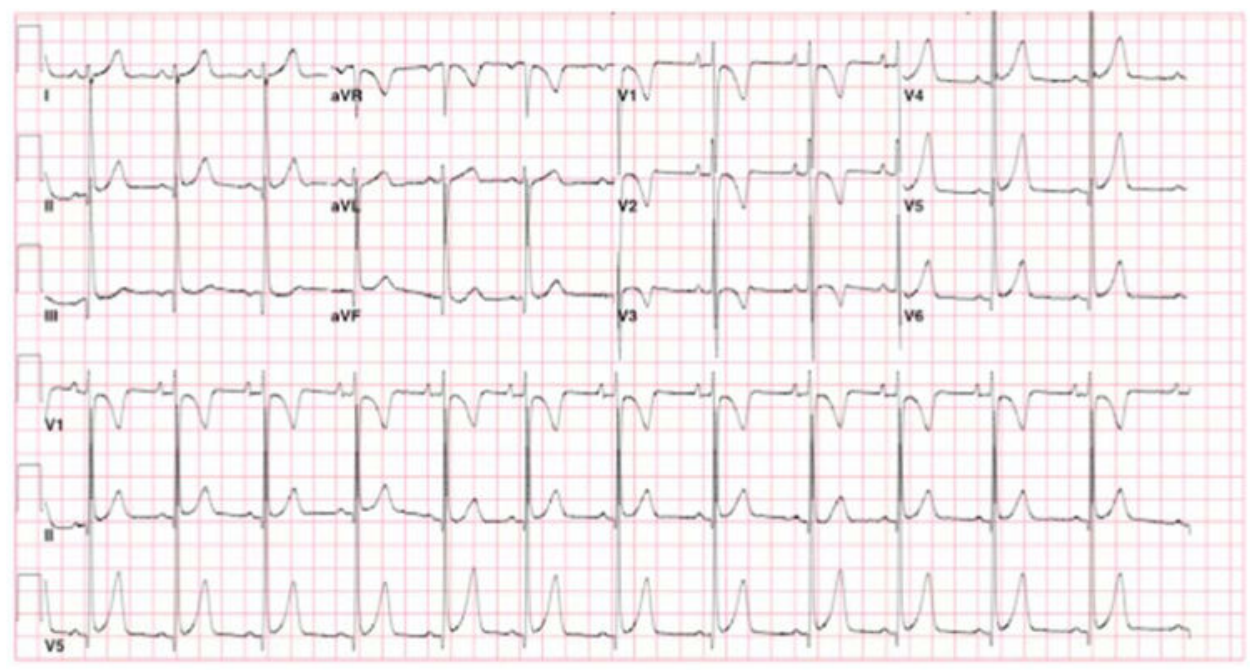

Figure 11.

Post-ablation ECG shows loss of delta wave. Right atrial abnormality, seen here, is a common finding in Ebstein's anomaly. Right bundle branch block is also common, although it is not seen in this case. 


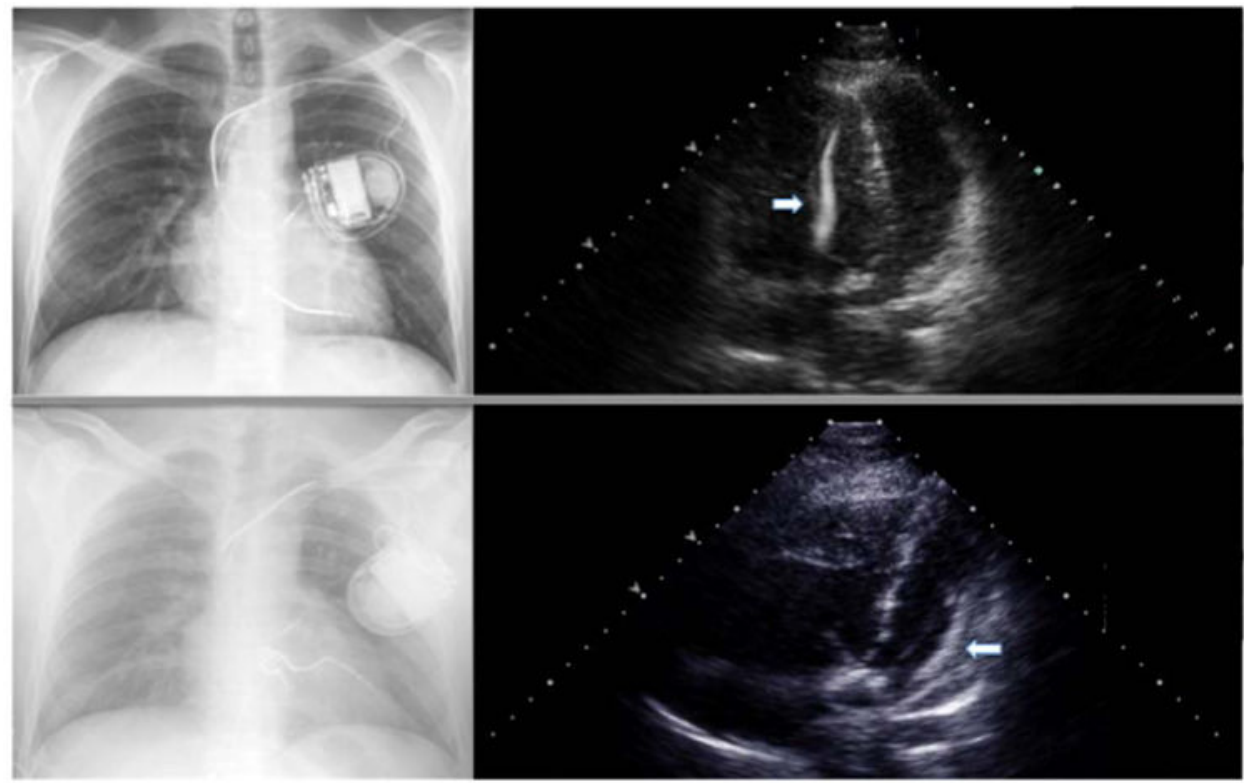

Figure 12.

Top: ICD lead (arrow) in RV (systemic ventricle) via Mustard baffle leak. Bottom: ICD lead (arrow) in LV (subpulmonic ventricle). Left - chest radiograph. Right - apical 4-chamber surface echocardiogram. 